\title{
A INSTRUÇÃO PROCESSUAL E A JUSTIÇA EFETIVA NO PROCESSO CONSTITUCIONAL MODERNO PUBLICISTA
}

\author{
BALDUR ROCHA GIOVANNINI
}




\title{
A INSTRUÇÃO PROCESSUAL E A JUSTIÇA EFETIVA NO PROCESSO CONSTITUCIONAL MODERNO PUBLICISTA
}

\author{
Baldur Rocha Giovannini ${ }^{1}$
}

\section{RESUM 0}

Constatou-se que o processo ainda está arraigado em al guns dogmas, como o da verdade formal, do formalismo e da manutenção de distância do juiz em relação à causa, como forma de preservar o princípio dispositivo e a independência do julgador. O sistema processual, porém, deve estar em constante busca da efetividade e publicidade do processo, em harmonia com o sistema constitucional da tutela efetiva ejusta. As normas processuais assim devem ser lidas sob a ótica da efetividade da jurisdiçãa, e mais voltadas para os seus escopos. As normas processuais, pois, devem dar concretude aos direitos fundamentais. ${ }^{2}$

Palavras-Chave: Efetividade da Jurisdição. Poder Instrutório. Processo Civil. Processo Publicista.

\section{ABSTRACT}

It was found that the process is still rooted in dogmas, as the formal truth of formal ismand maintenance away from thejudgein relation to the cause as a way to preserve the principle device and independence

\footnotetext{
1 Ex-Procurador Federal e ex-j uiz do Estado do Piauí. Atualmente exerce o cargo de Juiz de Direito no Estado do Tocantins. Pós-Graduado em Direito Civil e Processo Civil pela Universidade Católica do Tocantins. Email: baldur@tjto.jus.br ebrg98@hotmail.com

2 "En orden de importancia, administrar justicia constituye el primordial deber del juez. (...) La aplicacion de la ley, no significa una simple operación mecánica de subsunción de una regla abstracta, La sentencia judicial, es una norma individual, queimplica una verdadera creación jurídica, presupuesto que supone, que implica una verdadera creación jurídica, presupuesto que supone, como exactamente afirma Legaz y Lacambra, una elección dentro de ese margen de libertad que deja la ley, y la val oración de la conducta humana, que no constituye una operación lógica, sino un acto creador" (GERMÁN BAUCHÉ, 2011, p. 184-185, 2.v (grifo nosso).
} 
of the judge. The procedural system, however, must be in constant pursuit of effectiveness and advertising process in accordance with the constitutional system of effective protection and fair. The procedural rules so they should be read in light of the effectiveness of the jurisdiction, and thus more focused on their scopes. The rules of procedure, therefore, should give concreteness to fundamental rights.

Keywords: Effectiveness of the jurisdiction. Power instruction. Civil Procedure. Publicist Process.

\section{INTRODUÇÃO}

Atualmente, verifica-se uma grande criação legislativa e constante introdução de reformas processuais, com o qual se já pensa até na feitura de um novo Código de Processo Civil, porque as normas processuais não conseguiriam resolver o problema de eficácia do processo.

De se ver, contudo, que o sistema hermético e fechado de normas processuais não tem atendido ao verdadeiro sentido constitucional, qual seja, trazer solução prática para os conflitos levados ao Poder J udiciário.

Estar-seá, assim, abordando a necessidade de ver o processo sob o ângul o publicístico, pelo qual deve ser aberto ao poder criativo da jurisdição, não só do juiz, porqueo processo é formado por um conjunto deatores, que são as partes, advogado, serventuário ejuiz.

De se ver que o processo não pode mais ser visto sob a vertente privatista, no qual se busca somente a verdade formal, 
mas, ao contrário, deve ser um instrumento de busca e aplicação efetiva dos direitos e garantias fundamentais, e principalmente dos di reitos fundamentais (estes universais).

\title{
2 BREVE RESUMO DA DOUTRINA SOBRE OS PODERES INSTRUTÓRIOS DO JUIZ
}

O direito à prova eo poder instrutório de ofício têmsido temas que têm levado a doutrina a ostentar diferentes posições, uma defendendo, outra não, havendo também uma linha intermediária em menor grau.

Segundo Daniel Amorim Assumpção Neves, quanto ao direito à prova:

\begin{abstract}
"encontra-se na doutrina uma forte tendência na defesa da natureza constitucional do direito à prova, que, embora não esteja expressamente previsto no Texto Maior, seria decorrência da modema visão do princípio da inafastabilidade da tutela jurisdicional, previsto no art. 50, XXXV, da CF ('a lé não excluirá da apreciação do Poder Judiciário, lesão ou ameaça a direito'), atual mente anal isado à luz do acesso à ordem jurídica justa, desenvolvida no Capítulo 1 , item1.5.5". Diz também esse autor que "dentro dessa nova visão do princípio constitucional, visivelmente preocupada com a qual idade da prestação jurisdicional, encontra se o direito à prova, que garantirá o efetivo exercício do devido processo legal e do contraditório, ambos garantidos de forma expressa por nossa Constituição Federal, alçam o direito à prova no processo civil ao patamar constitucional". Conclui esse autor que "por mais importante que seja a busca e obtenção da
\end{abstract}


verdade al cançável, jamais poderá ser considerado que a busca da verdade seja o único objetivo no processo. Tal pensamento, além de indevidamente restringir-se a tão somente um dos diferentes escopos do processo, faria com que a busca da verdade fosse al go absoluto, sem limite, admitindo-se qualquer espécie de prova, produzida de qual quer forma, e em qualquer momento do processo, o queinclusivenos levaria de voltaà época da barbárie, com a admissão, por exemplo, da prova obtida medi ante ameaça ou tortura. A busca da verdade éo que legitima a atividade jurisdicional, mas não deve ser considerada um fim em si mesmo" (NEVES, 2011, p. 411).

Também importante mencionar que segundo entendi mento de Diego Martinez Fervenza Cantoario, a atuação di retiva do juiz deve ser supletiva à das partes somente quando vislumbrar eventual quebra da paridade de armas, dizendo que o juiz somenteintervém supletivamente para garantir a paridade de armas. Assim também ocorre porque as partes devem dirigir o processo. Ao final, esclarece este autor que o juiz não pode assumir posições autoritárias, mas sim respeitar a iniciativa probatória das partes. O juiz assim só deve, segundo disse, intervir excepcional mente na produção das provas pelas partes não requeridas. ${ }^{3}$

Destarte, tecidas essas considerações acerca da doutrina que admite o poder supletivo do juiz e a preocupação com a imparcial idade, passar-seá à análise da posição de que o juiz hoje é um juiz constitucional, eficazmente um dos garantidores

3 CANTOARIO, Diego Martinez Fervenza Poderes do juize eprincípio do contraditório. Revista de Processo, São Paulo, n. 195, p. 303-304, maio. 2011. 
dos direitos.

Assim, a atividade judicial, para que possa ser efetiva, dentro do seu comando constitucional, limitada certamente por outros princípios como o do contraditório e da ampla defesa, é essencial mente um instrumento de real ização de material ização de umajustiça concreta e efetiva, sem ser arbitrária.

Com a visão de um processo constitucional, não mais se justifica a classificação dos direitos em disponíveis e menos amparados, e a outra em direitos indisponíveis e devedores de maior amparo judicial. A Constituição igualmente diz que a propriedade é um direito fundamental, inscrito no artigo 50, caput, da Constituição Federal; além de outros direitos de não menosimportância. A liberdadesempropriedadeesemo mínimo existencial não éumaverdadeiraliberdade. $O$ direito àfelicidade, por sua vez, também está protegida constitucionalmente pela cláusula pétrea da digni dade da pessoa humana, mesmo que não escrito expressamente.

Nãosepodeol vidarqueadi visão entreverdadeformal ereal ou material, sobo prismaeàluz dajustiçareveladoradedireitos do homem, não se encaixa mais dentro do parâmetro constitucional, sendo a justiça o instrumento-garantia constitucional dos direitos fundamentais. Como tal, o processo deve assumir asuaverdadeira função: pacificar com justiça e equidade.

Não se desconhece, porém, que a busca da prova dentro do processo efetivo e constitucional, logicamente não pode ser autoritária a ponto de procurar a todo custo dar razão a uma das partes. Como no direito administrativo, o uso de um poder não 
pode ser exercido abusivamente, quando nesse ramo a chamada teoria do desvio de poder ou de finalidade é perfeitamente combatível; e no processo por vários outros meios, como a exceção de suspeição, caso seja flagrantemente abusiva a produção de ofício.

\subsection{A cláusula geral de poder instrutório}

Não há de se olvidar que, no sistema processual constitucional, o poder do juiz de dar impulsão às partes, com base no artigo 130 do Código de Processo Civil, é uma cláusula geral de tutela das liberdades, em prol da ordem jurídica justa, decorrente do direito de acesso à ordem jurídica justa, como diz Kazuo Watanabe, lição jamais esquecida, que, por ser constitucional, só pode ser justa. ${ }^{4}$ De se ver que a Justiça, no sistema constitucional, tem por dever promover o bem de todos e assegurar o exercício dos direitos sociais e individuais. Veja se que assegurar o exercício indica uma ação, na qual se coloca a Justiça, mas nos limites constitucionais é mais publicista e efetiva. A ação sob o ângulo privado com a negação de poderes de instrução ao juiz, mesmo sem iniciativa das partes, quando necessário, para assegurar ajustiça material, énegação do direito

$4 \quad$ Art. 5o, XXXV, da Constituição Federal:

"a lei não excluirá da apreciação do Poder J udiciário lesão ou ameaça a direito". Art. 3o da Constituição Federal:

“Constituem objetivos fundamentais da República F ederativa do Brasil:

I - construir uma sociedade livre, justa esolidária;

(...)

IV - promover o bemdetodos" (...).

Revista Esmat, Pal mas, Ano 5, ํo 5, pag. 33 a 52 - jan/jun 2013 
deacesso constitucional àjustiçaou princípio da inafastabilidade dajustiça'.

A isso, somarse o fato de outros dispositivos, exemplificativos, no Código de Processo Civil, demonstrarem a possibilidade de o juiz, no processo constitucional, determinar de ofício provas ${ }^{6}$ tendentes à configuração da efetividade da jurisdição. Sendo assim, o art. 130 do Códi go de Processo Civil deveser interpretado da maneira mais ampla possível, deacordo com uma interpretação conforme a constituição, podendo o juiz em qualquer caso determinar a realização de provas, quando necessário para assegurar a justiça real e igualitária, sem quebra de imparcialidade, pois o processo deve ser publicista e igual itário de forma material. ${ }^{7}$

Não se desconhece que parte da doutrina rechaça a plena aplicação do artigo 130 do Código deProcesso Civil, quando cita o art. 333 do mesmo Código, que trata do ônus da prova. Mas é de se ver que o ônus da prova se dirige às partes, e não ao juiz, sendo somente regra de jul gamento, que gera ônus para a parte

5 Art. 5o, XXXV, da Constitui ção Federal:

"A lei não excluirá da apreciação do Poder J udiciário lesão ou ameaça a direito".

6 "Finalmente, cabe agregar que, respecto de la naturaleza jurídica de las normas procesales que plasman o desarol lan el principio de moral idad, han discrepado radical mente los autores (...).

CALAMANDREI afirma que se trata de una carga procesal sui géneris porque puede resolverse no en una egoísta defensa del interés propio, sino en una ventaja para el adversario y, en todo caso, en una una colaboración para la justicia. Por lo mismo, cabe recordar que la teoría de la carga procesal es un producto del liberal individualismo procesal y que es un aporte personal de James GOLDSCHMIDT" (E.C. BORTHWICK, Adolfo. Principios formativos de los procesos. Corrientes: Mario A. Vieira Editor, 2005, p. 32.

7 BEDAQUE, José Roberto dos Santos. Poderes instrutórios do juiz. 3ạ ed. São Paulo: RT, 2001, p. 159. 
que tinha o ônus da prova, mas não diz (em momento algum) que o juiz é limitado pelo artigo 333 do Código de Processo Civil.

Deve-se registrar, porém, que os poderes instrutórios ativos sofrem a limitação do princípio de tratamento igual entre as partes e a vedação de surpresa, no processo. As regras de distribuição do ônus da prova, pois, devem ser objeto de preocupação no momento processual de proferimento da sentença. O ideal de justiça voltado para o bem comume para a justiça social jamais será atingido, conforme Bedaque, enquanto o juiz estiver privado de poderes instrutórios, sendo mero coadjuvante do processo.

\subsection{Do processo publicista}

Nesse mesmo contexto, à luz da noção do processo publ icista e consoante o princípio da efetividade da jurisdição, o processo moderno constitucional tende a caminhar para a ampliação dos poderes instrutórios do juiz. Apesar de certa resistência quanto à entrega de poderes instrutórios do juiz, essa visão é fruto da visão privatista do processo, que hoje deve ser mais publicista. ${ }^{8}$

Segundo Rafael Motta e Correa apud J osé Roberto dos Santos Bedaque, com a natureza pública do processo, está superada a visão privatista do processo, cuja finalidade

8 DIDIER JUNIOR, Fredie; BRAGA, Paula Sarno; OLIVEIRA, Rafael. Curso de direito processual civil. Sal vador:Podium, 2007, p. 52, 2.v.

Revista Esmat, Palmas, Ano 5, o5, pag. 33 a 52 - jan/jun 2013 
é a atuação do direito objetivo, sendo a proteção de direitos subjetivos consequência natural. ${ }^{9}$

Desever que, conforme ministra Rafael Motta e Correa, "a publicização do processo deve ser entendida como uma tendênciamundial, inclusivenospaísesemquematériasdedireito público devemser discutidas em contencioso administrativo". ${ }^{10}$

Nesse sentido, Mauro Capelletti tem dito que o juiz deve exercer a direção material do processo, e não a simples direção formal. Tal fato tem relação com o escopo social e político da jurisdição, de forma que haja distribuição de justiça igualitária, justa, efetiva e antes de tudo acessível a todos. O juiz, assim, depois de iniciado o processo, deve determinar o ritmo e o impulso deste, já que, "da circunstância de al guém dispor da relação jurídica de direito material controvertida, não se infere necessariamente que passa a di spor da rel ação jurídica processual , a qual édistinta evivesob o signo publicístico, enão sob o signo privatístico". ${ }^{11}$

\section{O PROCESSO MODERNO E OS ESCOPOS DA JURISDIÇÃO}

Sabe-se que o processo tem como escopos: a) escopos sociais \{pacificação com justiça, educação\}; b) políticos

9 CORREA, Rafael Motae. Poderes instrutórios do juiz eas novas di retrizes da norma processual. R evista de Processo. São Paul o: Revista dos Tribunais, n. 194, p. 329, abr. 2011. 10 Op. Cit, p. 329.

11 MOREIRA, J osé Carlos Barbosa. O juiz ea prova. R evista de Processo. São Paulo: Revista dos Tribunais 35/178. 
\{liberdade, participação, afirmação da autoridade do Estado e do seu ordenamento \}; e c) jurídico \{atuação da vontade concreta do direito .

A jurisdição é uma função do Estado, e este a exerce por meio de um dos seus poderes (Poder J udi ciário); o processo é o instrumento formal da jurisdição e também o meio de atuação da vontade concreta do Direito objetivo. De forma moderna, a doutrina enxerga a instrumentalidade do processo sob aspecto positivo. Desse modo, o processo recai como instrumento do qual se vale o Estado, a fim de alcançar os escopos da jurisdição. Esta, por sua vez, éuma manifestação do poder estatal soberano; os escopos da jurisdição são classificados em três categorias: sociais, políticos ejurídicos.

O primeiro deles, os escopos sociais: neste âmbito, temse o processo como meio relevante para a solução de conflitos existentes ou que venham a surgir na sociedade. Em situações emque hálide, o exercício jurisdicional deveatuar no sentido de compor o conflito. Essa pacificação deve ser feita com justiça, de maneira adequada ao direito objetivo, observando-se o fim social para o qual a lei se destina, e ao bem comum. O Estado, no exercício da função jurisdicional, dentro desse escopo social, deve buscar educar a sociedade.

O segundo, o escopo jurídico da jurisdição consiste em atuar a vontade concreta do Direito objetivo; o Estado na atividade da jurisdição detém a finalidade de manter a integridade do ordenamento.

No terceiro escopo, a jurisdição é uma manifestação do 
poder estatal, portanto, advém de natureza política; o Estado tem a necessidade de afirmar tal poder, porque sem este seria impossível impor condutas aos jurisdicionados. No exercício jurisdicional existem objetivos de assegurar e observar os direitos fundamentais, sendo assim, há garantia fundamental protegida constitucional mente aos cidadãos.

Nessa perspectiva, passarse a fal ar em um Estado Social de Direito preocupado não só com a segurança jurídica, mas também com os ideais de justiça e igualdade, mobilizados especial menteparagarantiaeefetivação dos direitoseconômicos, sociais e culturais.

Reconhecese também que o Estado de direito, como garantia das liberdades, é pré-condição para que as pessoas possam deliberar livremente sobre a coisa pública e, dessa forma, existir democracia efetiva. Chama-se a atenção, contudo, para o fato de que as liberdades não bastam para assegurar a existência de uma deliberação pública realmente justa. A igual dade material e algumas propostas oriundas do Estado social constituem também pré-condições para deliberação pública. Afinal, um indivíduo sem acesso à educação ou à saúde encontra-seem desvantagem no complexo jogo deargumentose contra-argumentos que envolvem a del iberação pública.

Sendo assim, pelateoriado Estado moderno edos escopos da jurisdi ção, ganha mais força o papel do poder criativo emais publicista da jurisdição. 


\subsection{0 processo instrutório à luz do E stado Democrático de Direito}

Com grande sabedoria, o ilustre doutrinador Alexandre Freitas Câmara enfrenta a questão dos poderes instrutónios do juiz à luz do Estado Democrático de Direito, e se manifesta no sentido de que o juiz constitucional, como parte do modelo de Estado engendrado pela Constituição, éessencial mente ativo na busca da verdade eatua na correta atuação da vontade do di rei to objetivo nos casos concretos submetidos à apreciação do Poder Judiciário. Ensina ainda que, para se al cançar esse desiderato, impõe-se o reconhecimento de amplos poderes de iniciativa probatória do juiz, permitindo-se que esse agente estatal cumpra sua missão constitucional de fazer justiça. Explica, pois, Alexandre Freitas Câmara que a correta interpretação quanto ao art. 130 do CPC é a de que leva à afirmação de amplos poderes de iniciativa provatória do juiz, porquenão removeaimparcialidade deste. Não sabe, pois, o juiz a quem a prova pode beneficiar antes de produzi-la. A não produção da prova, tambémé, por si só, uma parcialidade, quando se queda inerte. A verificação de conformidade do art. 130 do CPC passa pela sua interpretação finalística à luz do princípio do Estado Democrático de Direito, como Estado Social de Direito, solucionando os problemas das condições materiais da existência de forma eficaz. Esse Estado Social de Direito deve programar a igualdade material, e não somente formal, val orizando a dignidade, cidadania e digni dade da pessoa humana, nos termos dos arts. 1o e $3^{\circ}$ da Constituição

Revista Esmat, Palmas, Ano 5, o5, pag. 33 a 52 - jan/jun 2013 
Federal \{construir uma sociedade justa, livre e solidária, erradicar a pobreza e reduzir as desigualdades regionais e sociais, promovendo o bem de todos\}. O Estado constitucional, pois, éativo, enão passivo. ${ }^{12}$

\section{A IMPARCIALIDADE NEGATIVA E POSITIVA E 0 PROCESSO OBJETIVISTA}

Registre-se, também, que a imparcialidade pode ser positiva ou negativa, não havendo razão para negar os amplos poderes instrutórios do juiz, no processo publicista \{parte do modelo de constitucionalismo social e efetivo\}.

Sem embargo, dentro da feição positiva e negativa da imparcialidade, a primeira é resultado de que o princípio da imparcialidade não é um fim em si mesmo, devendo conviver comoutros princípios constitucionais, como o de sol idariedadee de construção de uma sociedadejusta efraternal . A Constituição, logicamente, preconiza o aspecto positivo daimparcial idade, que é justamente o agir material do juiz, com vistas a construir uma sociedademais justa, consi derando os instrumentai snecessários. O viés negativo da imparcial idade visa evitar que o juiz atue em favor de determinada parte. Quando a Constituição, sob o princípio da máxima efetividade, veicula princípios norteadores do Estado, vincula todos os poderes estatais, como o Judiciário. $\mathrm{O}$ aspecto positivo da imparcialidade traz um mandamento de

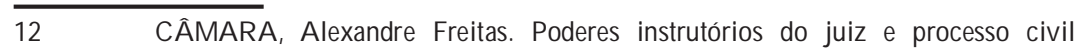
democrático. R evista de Processo, São Paulo, n. 153, nov. 2007.

Revista Esmat, Palmas, Ano 5, № 5, pag. 33 a 52 - jan/jun 2013 
ação para o juiz. Não se pode deixar de registrar que a equitas já previa o agir do magistrado, conjugado como princípio deacesso à ordem jurídica justa. Em síntese, a parcial idade positiva nada mais é do que a própria humanização e aplicação dos direitos fundamentais no processo jurisdicional. Assim, a simples produção de ofício de prova e condução ativa do processo pelo juiz não pode conduzir à ideia de parcialidade. ${ }^{13}$

Desta feita, o processo, como processo constitucional objetivo ${ }^{14}$ ou publicista, quevise a produzir umajustiça material e efetiva, impõe que o juiz deve ser tanto imparcial negativo, em primeiro momento, como parcial positivo, em segundo momento, humanizando-se e efetivando as normas processuais.

\subsection{Unidade do sistema probatório}

Sesepensar como ensina Norberto Bobbio, queo sistema jurídico é único e possui uma base comum, coerente e pleno, sendo a teoria geral do processo uma só, não vemos sentido na afirmação corriqueira de que no processo penal a verdade é real e no processo civil éformal. A esse respeito, ensina que as normas queintegramo ordenamento devemestar de acordo com

13 SOUZA, Artur César de. A parcialidade positiva do juiz. Revista de Processo, São Paulo, n. 183, 2010, p. 67-76, mai. 2010.

14 Dentro da visão humanitária do processo: “(...) (4) El proceso es una institucion social: los intereses que en él se hal lan en juego lo transcienden; (5) Ninguna cuestión litigiosa en y durante se arropa en comportimentos estancos; están intercomunicadas en una sucesión no sólo coordi nada sino interdependiente cuya aplicación global demanda recorrer y computar el conjunto de sus fases o tramos; e resultado es la derivación de esta totalidad; 6) Humanizar e proceso es personalizarlo; en fin, socializarlo con los aires más generosos de la solidariedad (...)" (MORELLO, Augusto. El proceso justo. Buenos Aires: A beledo-Perrot, 1994, p. 16 e 17. 
o princípio da unidade (tradução do autor). ${ }^{15}$

Nesse sentido, Alexandre Freitas Câmara, apud outros autores, explica que no sistema processual penal está superada a questão de possibilidade do poder instrutório do juiz, não se podendo admitir que seja diferente no processo civil, sob pena de ser "absolutamente esquizofrênico". ${ }^{16} 17$

Restaesclarecer queosistemajunídico processual édotado de globalidade, interação e retroalimentação no que permite à atividade de iniciativa processual, cujas características são: a) globalidade: o sistema deve se comportar hamonicamente; b) não somatividade: o sistema não se constitui de simples somatório das partes; c) interação: influência recíproca de seus elementos; d) retroalimentação: ocorrem alterações decorrentes de ações do próprio sistema. ${ }^{18}$

Assim, a liberdade probatória do juiz no processo penal não pode ser diferente da do processual civil, e em ambas a imparcial idade éa mesma.

\section{CONCLUSÃO}

Podese ver que o sistema tem reagido à morosidade judicial modificando a legislação para criar súmulas vinculantes

\footnotetext{
15 MIRANDA, Carmen Maria Garcia. Cuardenos Electrónicos de Filosofía Del Derecho. Disponível em: www.uv.es/CEFD.

16 Op. cit, p. 45.

17 ALVARADO VELLOSO, Adolfo. Debido proceso versus pruebas de oficio, p. 310.

18 LOPES, J oão Batista; LOPES, Maria Elizabeth deCastro. Novo Códi go de Processo

Civil e efetividade da jurisdi ção. R evista de Processo, São Paulo, n. 188, p. 168, 2010.
}

Revista Esmat, Pal mas, Ano 5, ํ5, pag. 33 a 52 - jan/jun 2013 
ejul gamento derecursos repetitivos, mas ao mesmo tempo corre o risco de, se levado ao extremo, retirar a finalidade principal do processo que é trazer a justiça e pacificação social.

Caso o sistema fosse concebido sob o manto do processo publicista, posto o processo ser constitucional edeveser efetivo, uma vez presente dentre as garantias constitucionais (art 5o, XXXV, da Constituição Federal), não haveria necessidade de tantas reformas processuais, porque se adequaria nomalmente ao caso concreto.

Destarte, o processo dentro de sua visão constitucional, precisa ser efetivo, como meio de dar concretude aos direitos fundamentais. Assim, também dentro da ideia de que a ação é uma face do direito constitucional de petição, tal como já ocorre no processo penal.

Diante da cláusula constitucional da inafastabilidade do exercício da jurisdição e do princípio do estado democrático de direito, as normas processuais devem ser interpretadas, extraindo-se delas sua máxima efetividade, por ser o processo publicista, garantindo o bem comum. A mudança da legislação processual sem a mudança de paradigma não trará a al mejada satisfação social, pacificação dos conflitos, confiança nas leis e melhor qualidade da prestação jurisdicional. A legislação processual, assim, como instrumento de satisfação de direitos, deve atender aos fins constitucionais, dando a cada um o que é seu, com base na concepção aristotélica de justiça. A verdade e a justiça não podem ser pela metade, têm de ser efetivas e concretas. Da mesma forma, vêse imperioso que, mais que 
reformas processuais, sejam dadas mais abertura e flexibilidade para as normas processuais, permitindo maior poder criativo e mai or porosi dade para incidência dos princípios constitucionais, conforme princípio da efetividade da tutela jurisdicional e da natureza pública do processo, como constitucional que deveser, emessência.

Dessa forma, a interpretação da norma processual no sentido da máxima efetividade, com a visão publicista das normas, trará a humanização necessária para a legislação processual, fazendo do processo um instrumento que conduza à felicidade e à confiança.

\section{REFERÊNCIAS BIBLIOGRÁFICAS}

CÂMARA, Alexandre Freitas. Poderes instrutórios do juiz e processo civil democrático. R evista de Processo, São Paulo, n. 153, p. 33-46, nov. 2007.

CANTOARIO, Diego Martinez Fervenza. Poderes do juiz e princípio do contraditório. Revista de Processo, n. 195, p. 279304, mai. 2010.

CORREA, Rafael Motta e Poderes instrutórios do juiz e as novas diretrizes da norma processual. R evista de Processo, $\mathrm{n}$. 194, p. 323-348, abr. 2011. 
DIDIER JR, Fedie. Cláusulas gerais processuais. Revista de Processo, n. 187, p. 69-83, set. 2010.

MORAIS, Dalton Santos. A atuação judicial criativa nas sociedades complexas e pluralistas contemporâneas sob parâmetros jurídico-constitucionais. Revista de Processo, $p$. 55-94, fev. 2010.

NEVES, Danie Amorim Assumpção. Manual de Direito Processual Civil. 3. Ed. São Paul o: Método, 2011.

SOUZA, Artur César de A parcialidade positiva do juiz. R evista de Processo, n. 183, p. 25-76, mai. 2010.

W. PEYRANO, Jorge. El cambio de paradigmas en materia procesal civil. Revista de Processo, n. 184, p. 154-162, jun. 2010. 